\title{
The Acceptance Model of QR Code Payment Systems in Thailand: A Proposed Model
}

\author{
Benjaporn Witchutawon, Wornchanok Chaiyasoonthorn ${ }^{+}$and Singha Chaveesuk $^{+}$ \\ Faculty of Administration and Management, King Mongkut's Institute of Technology Ladkrabang, Bangkok, \\ Thailand
}

\begin{abstract}
Technological developments have been playing an important role in the economic system of countries. In order to further propel the Thailand economic system, the government has a national e-payment master plan to support standardized e-payment systems conforming to existing technology. The QR code payment system is one of the national e-payment master plan which the government is trying to push to take Thailand into a cashless society. QR code payment system for citizens in Thailand is very new technology and yet does not have many users. Thus, the purpose of this research is to develop the conceptual framework on QR code payment system in Thailand to initially identify relevant factors which influence the intention to use it for making payments. The research framework has been developed by integrating the Unified Theory of Acceptance and Use of Technology (UTAUT) with trust, perceived risk (PR) and personal innovativeness in information technology (PIIT). Finally, the contribution of this study provides potential factors that could affect the acceptance of QR code payment systems in Thailand.
\end{abstract}

Keywords: QR code payment acceptance, Unified theory of acceptance and use of technology, UTAUT, Trust, Perceived risk (PR), Personal innovativeness in information technology

\section{Introduction}

Technological advancements play a major and functional role in facilitating and changing the lifestyle of many people. In order to move forward and to have further developments, the Thai government has implemented "Thailand 4.0" policy. Thailand government started developing a national e-payment master plan through which government is trying to push an electronic payment (e-payment) system in the country [1]. The Bank of Thailand is encouraging customers to make transactions through e-payment since beside other benefits; e-payment would reduce cost in currency printing, reduce point of sale (POS) terminals and have faster transactions saving time.

The QR code has two-dimensional barcode which contains much greater amount of data in a small space and can be read at very high speeds [2]. The QR code payment, as a new payment method, has been rapidly evolving all over the world since QR code payment has feature high quickness, easiness, and security [3]. China has made good progress in QR code payment compared to other countries. Its growing use and popularity makes it feasible to live in China today without having the need to carry the cash currency notes for buying goods and services. [4]

The Bank of Thailand has launched standard QR code payment system aims at spurring Thai economy and facilitating Thailand's transformation move towards a cashless society. The standardized QR code can be seen as an overcome solution for customers and merchants, as merchants can display a single QR code for payments, while consumers can scan QR code from any banking application in their mobile devices [5]. The use of cash and payments through e-payments goes simultaneously by consumers at the present state of development. There are huge numbers of transactions wherein consumer still uses cash to pay for goods and

\footnotetext{
+ Corresponding authors. Tel.: + 662-3298460; fax: +662-329-8461.
}

E-mail address: Wornchanok.ch@kmitl.ac.th; Singha@it.kmitl.ac.th. 
services. The UnionPay International (2018) has conducted survey titled "The Future of Payment in Thailand" in which the results points that 87 percent of consumers' still prefer to pay for goods and services through cash rather than any e-payment [6]. Although, the QR code payment system has been very successful in China, it is still new for customers and merchants in Thailand. The government and private sector are trying to promote and create an environment for acceptance among their citizens for the new technologies and particularly the use of QR code payment system [1].

In this research paper, the Unified Theory of Acceptance and Use of Technology (UTAUT) have been used to investigate factors influencing the intention to use $\mathrm{QR}$ code payment system in Thailand. Other variables including the integration with trust, perceived risk (PR) and personal innovativeness in information technology (PIIT) are used as base models with appropriate independent variables for this study. The dependent variable is intention to use QR code payment. Consequently, this research will help to ascertain the appropriate model for intention of using the $\mathrm{QR}$ code payment system on the available theories.

\section{Literature Reviews}

\subsection{The unified theory of acceptance and use of technology (UTAUT)}

Venkatesh et al. [7] proposed the unified theory of acceptance and use of technology (UTAUT) which were used to describe acceptance and use of new technology. UTAUT is consolidated from eight model used in the information system (IS) field. UTAUT has been developed to explain the technology acceptance in organizational context.

Venkatesh et al. [8] further proposed the extension of UTAUT to UTAUT2 to study the technology acceptance among consumer context. UTAUT has four determinants which include performance expectancy, effort expectancy, social influence and facilitation condition. However, based on further model of acceptance contexts, three new determinants were added as part of UTAUT2 namely hedonic motivation, price value and habit. Whereas, the result studies of Oliveira et al. [9] shown that hedonic motivation and price value not influencing in the context mobile payment and habit was not bring used because QR code payment system is a new technology tool that has not yet gained extensive use among masses.

Therefore, this research purposes UTAUT which contains four determinants which are performance expectancy (PE), effort expectancy (EE), social influence (SI) and facilitation condition (FC) as a theoretical framework to initially investigate factors on the use of QR code payment system. It has been found that there are 3 main factors that directly influences the behavior intention to use technology i.e. PE, EE and SI. While FC directly influences use behavior and also found that behavioral intention (BI) has a direct influence on use behavior as shown in Fig 1. The UTAUT provide insights in users' intention to use and behavior up to the extent of 70 percent more than the eight model analysis [7]

However, three additional variables have been considered, includes trust, perceived risk, and personal innovativeness in information technology (PIT) of use that affects the intention and use of technology [9][10][11].

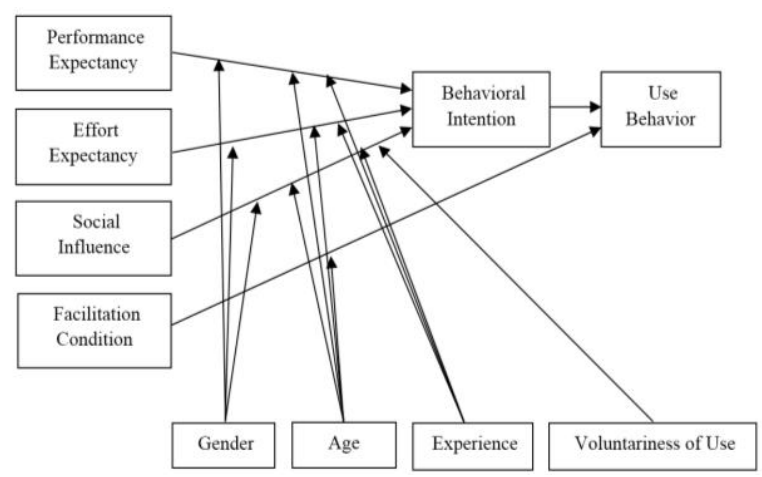

Fig 1: The Unified Theory of Acceptance and Use of Technology (UTAUT)

\subsection{Trust}

Trust plays a major role in information systems (IS) because acquiring trust reduces fears and worry of users [10]. Most IS research has investigated the factor of trust in individual decisions to acceptance and use 
technology and found that users trust in people more than trust in technology [12]. Trust in context mobile payment is required to have a belief that in the forgoing transaction all the parties would fulfil their engagement. This plays an important role in financial transactions since the process of electronic payment carries confidential information such as money and personal information will be safe and that the parties involved will not act with spurious actions with the access of personal information or risk losing money [12][13].

\subsection{Perceived risk (PR)}

Perceived risk (PR) is a major factor that has been found in many studies in context of mobile payment [11][14-18]. Tossy [17] define PR in context mobile payment is perceived uncertainty about possible negative consequences of using mobile payment system. PR is uncertainty and risk related to use of mobile payment that is measured from non-monetary expense that consumer have to carry and at the same time consumer has monetary expense for an actual mobile payment e.g. transaction fee [10]

\subsection{Personal innovativeness in information technology (PIIT)}

Personal innovativeness in information technology (PIIT) is a construct that has been proposed by Roger [19] and categorized the characteristics of the adopter into 5 categories consisting of innovators, early adopters, early majority, late majority and laggards. Many research have suggested personal innovativeness plays a major role for technology adoption in domain of IT and applies it as an independent variable [9][11][15]. In IT context, personal innovativeness in information technology (PIIT) is the willingness of an individual to try out any new information technology and will accept technology faster than others [20]. Innovative individuals are more curious and enthusiastic in looking for information. They will search more information about a new technology to comprehend it before they use and think of the technology as more gainful than less innovative individuals. Therefore, high innovativeness person will be less affected by the complications of the new technology than low innovativeness person [14].

\section{Hypothesis Development and Conceptual Framework}

This study aims to investigate factors influencing the intention to use QR code payment system in Thailand by constructing the conceptual frameworks from the literature review on UTAUT, trust, perceive risk (PR) and personal innovativeness in information technology (PIIT) in context of mobile payment, theoretical justification of the hypothesis are as below.

Behavioral intention (BI) defined as the degree of the individual's intention to use a new technology. BI is one of the most significant factors that influence the use behavior [7]. All of the model in the UTAUT study use behavior intention as a dependent variable in investigation of individuals to accept new technology which can be found in various studies about technology particular in the context mobile payment [9][15][21]. $\mathrm{BI}$ is a dependent variable that is influence by independent variables that the independent variables influence $\mathrm{BI}$ is PE, EE, SI, FC, trust, PR and PIIT.

Performance expectancy (PE) defined as the level to beliefs of individuals who believe that using technology will procure benefits and help increase work efficiency [7]. The study of Oliveira et al. [9] and Slade et al. [11] have found PE influencing the intention to use mobile payment. PE will be measured by the perceptions of using QR code payment system in terms of benefits, such as saving time, convenient etc. [22]. Since UTAUT model supports the assumptions that PE and BI are correlated, this study hypothesized that:

H1: Performance expectancy has positive affect on behavioral intention to use QR code payment system.

Effort expectancy (EE) defined as the level of perceived ease of individuals when using of technology [7]. Venkatesh et al. [23] confirm that EE influences the satisfaction of individuals and impacts the intention to use technology. The study of Teo et al. [21] has found EE influencing the intention to use mobile payment. EE will be measured by the perceptions of ease of use by the QR code payment system and easy of learning how to use this payment system [22]. Since UTAUT model supports the assumptions that EE and BI are correlated, this study hypothesized that:

$\mathrm{H} 2$ : Effort expectancy has positive influence on behavioral intention to use QR code payment system. 
Additionally, the study of Oliveira et al. [9] and Teo et al. [21] have found that EE has positive impact on $\mathrm{PE}$ and has an indirect influence the intention through PE of mobile payment. Since UTAUT model supports the assumptions that EE and PE are correlated, this study hypothesized that:

H3: Effort expectancy has positive influence on performance expectancy of QR code payment system.

Social influence (SI) defined as the level of perception of each individuals believe that important people (e.g. friends and family) think that they should or should not use new technology [7]. The study of Slade et al. [11], Rakhi and Mala [15] and Tossy [17] have found SI influencing the intention to use mobile payment. SI will be measured by the perception of how friend, family, organization and important individual have influencing the intention to use QR code payment system [22]. Since UTAUT model supports the assumptions that SI and BI are correlated, this study hypothesized that:

$\mathrm{H} 4$ : Social influence has positive influence on behavioral intention to use QR code payment system.

Facilitating conditions (FC) defined as the level of belief of users who believe in the organization's infrastructure, facilities or instrument will help support the use of new technology [7]. If an operational infrastructure exists and support the use of technology, the behavioral intention to use technology will increase [9]. The study of Teo et al. [21] has found FC influencing the intention to use mobile payment. FC will be measured by the perception of availability of resources needed of using QR code payment system [22]. Since UTAUT model supports the assumptions that FC and BI are correlated, this study hypothesized that:

H5: Facilitating conditions has positive influence on behavioral intention to use QR code payment system.

Trust is a confidence of individuals in providers that an honest transaction processing, secure, uphold privacy by not propagating the personal information to unauthorized person [24]. Lack of trust in technology is an obstacle to consumer's to use new technology [25]. Studies in the mobile payment context also represent that trust is a main factor on behavioral intention to use mobile payment [18][26]. Since the hypothesized that:

H6: Trust has positive influence on behavioral intention to use QR code payment system.

Perceived risk (PR) from using mobile payment systems will diminish the intention to use of payment system [10]. Since the risk is higher as if the users loses their mobile phone device or information being stolen by the other person or unauthorized personnel. Therefore, the perceived risk has a great impact on the behavioral intention [14]. Studies in the mobile payment context represents that PR is obstacle on behavioral intention to use mobile payment [10][11][16][17]. Since, PR is obstacle the use QR code payment system the hypothesized that:

H7: Perceived risk has negative influence on behavioral intention to use QR code payment system.

Additionally, the study of Slade et al. [11] and Tossy [17] and Lee and Song [27] found also that trust has negative effect on perceived risk and have an indirect influence the intention through perceived risk of mobile payment. Most of the users tends to use a technology when they perceive that technology use has low risk [27]. Trust can help deduce high perception of risk which help user not to worry about risk from using the technology [11][27]. Since the assumptions that Trust and PR are correlated, this study hypothesized that:

H8: Trust has negative influence on perceived risk to use QR code payment system.

Personal innovativeness in information technology (PIIT) Agarwal and Prasad [20] believe that the factor that influence the knowledge of the information technology of that person are related to individual behavior. Personal innovativeness is a characteristic of each individuals who like the challenges and risks that exist in some individuals [20]. Studies in the mobile payment context utilize PIIT as an independent variable and also represent that PIIT is a main factor influencing the intention to use mobile payment [9][11][14][15]. Since the hypothesized that:

H9: PIIT has positive influence on behavioral intention to use QR code payment system

This study has developed a model to ascertain the factors influencing the intention to use QR code payment system in Thailand by using UTAUT model. Furthermore, three more variables are incorporated: trust, perceived risk and PIIT. These three variables are important for using the new technology. Therefore, 
this study has been based on UTAUT with trust, perceived risk and PIIT. A conceptual framework has been proposed and can be seen in Fig. 2

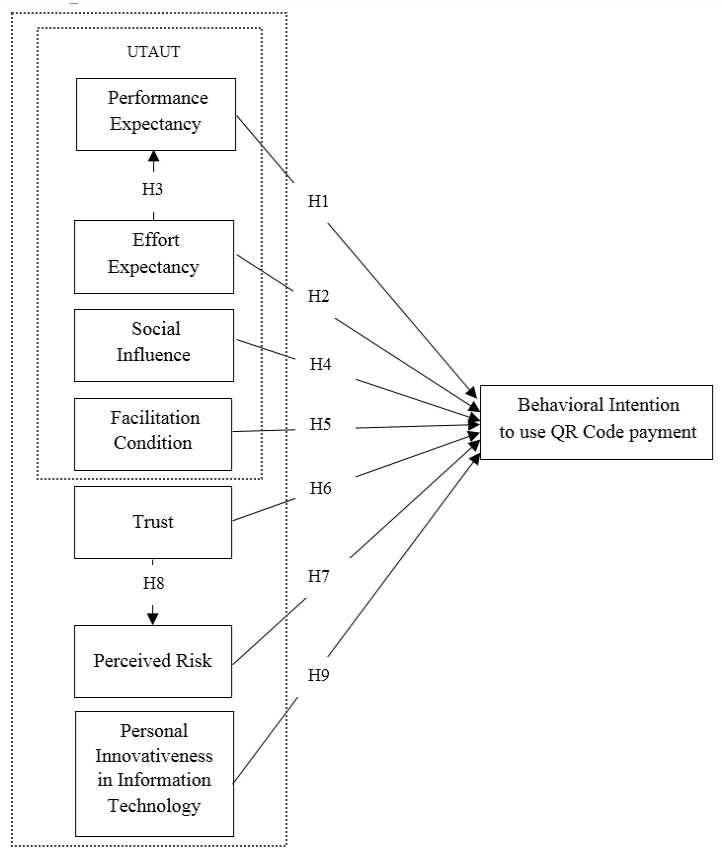

Fig 2: A Conceptual Framework

\section{Contributions and Conclusion}

The purpose of this study is to propose a conceptual framework of the QR code payment system acceptance in Thailand and to investigate the potential factors affecting this acceptance. This framework has been developed by the theoretical review based on the UTAUT model, incorporating three additional variables including trust, PR, and PIIT to ensure reliability and validity of all initial variables measured in the model. The results obtained in this study are to generate the conceptual framework in order to use as a tool to explore the QR code payment system acceptance. Further, this study will collect data from people in Thailand using questionnaires for further investigating factors influencing the intention to use QR code payment systems. The model will provide as a helpful understanding of factors and predict user's intention to accept QR code payment systems in Thailand.

\section{References}

[1] S. Pimphun and I. Srisomruk. Factor Influencing the Adoption and Use of PromptPay Electronic Payment Service. Business Administration Journal. 2018, 41(158): 1-18.

[2] K. Boonying and R. Chalida, Factor Affecting Adoption versus Behavioral Intention to Use QR code payment Application. College of Management. Mahidol University.

[3] P. Zhang. Why QR code payment develop well in China?. School of Computer Science, University of Birmingham.

[4] L. Nophakhun, 2018. Nationwide e-payments to push cashless society goal, Available form: http://www.Nation Multimedia.com/detail/.business/30335150.

[5] Bankingfrontiers, 2017. Thailand to have standardized QR code. Available form: http://bankingfrontiers.com/ thailand-standardized-qr-code/.

[6] Marketingoops. 2018. Reveals QR Code Trends for Thai Cashless Society Spending, Available: https://www. marketingoops.com/news/biz-news/qrcode-mobilepayment/.

[7] V. Venkatesh. M-G. Morris, D. Gordon B. and D. Fred D. User Acceptance of Information Technology: Toward a Unified View. MIS Quarterly. 2003, 27(3): 425-478.

[8] V. Venkatesh, J. Thong, and X. Xu, Consumer acceptance and use of information technology: extending the unified theory of acceptance and use of technology. MIS Quarterly. 2012, 36(1). 157-178. 
[9] T. Oliveira, M. Thomas, G. Baptista and F. Campos. Mobile payment: Understanding the determinants of customer adoption and intention to recommend the technology. Computers in Human Behavior. 2016, 61: 404-414.

[10] Y. Lu, S. Yang, Y.K. Patrick and Y. Cao. Dynamics between the trust transfer process and intention to use mobile payment services: A cross-environment perspective. Information \& Management. 2011, 48(8): 393 - 403.

[11] E.L. Slade, Y.K. Dweivedi, N.C. Piercy and M.D. Williams. Modeling Consumers' Adoption Intentions of Remote Mobile Payment. Psychology \& Marketing. 2015, 32(8): 860-873.

[12] D.H. Mcknight, M. Carter, J.B. Thatcher and P.F. Clay. Trust in Specific Technology: An Investigation of Its Components and Measures. ACM Transactions on Management Information Systems (TMIS). 2001, 2(2): 12-25.

[13] T. Tsiakis and G. Sthepanides. The Concept of Security and Trust in Electronic Payment. Computers \& Security. 2005, 24: 10-15.

[14] L.K. Foon. Comparison of Consumers' behavioral intention towards Credit Card Mobile Payment and Octopus Mobile Payment in Hong Kong. Information Systems and e-Business Management Concentration. Bachelor of Business Administration. Hong Kong Baptist University. 2014.

[15] T. Rakhi and S. Mala. Adoption readiness, personal innovativeness, perceived risk and usage intention across customer groups for mobile payment services in India. Internet Research. 2014, 24(3): 369-392.

[16] P. Hongxia, X. Xianhao and L.Weidan. Drivers and Barriers in the Acceptance of Mobile Payment in China. Comunications in Information Science and Management Engineering. 2011, 1(5): 73-78.

[17] T. Tossy. Modelling the Adoption of Mobile Payment System for Paying Examination Fees in Tanzanian Major Cities. International Journal of Computing and ICT Research. 2014, 8(1): 83-98.

[18] Fernanda F.O. Malaquias and Y. Hwang. Trust in mobile banking under conditions of information asymmetry: Empirical evidence from Brazil. Informantion Development. 2016, 32(5): 1-13.

[19] E.M. Rogers. Diffusion of Innovations. New York: The Free Press, 1983.

[20] R. Agarwal and J. Prasad. A Conceptual and Operational Definition of Personal Innovativeness in the Domain of Information Technology. Information Systems Research. 1998, 9(2): 204-215.

[21] A.C. Teo, Garry, W.H. Tan, K.B. Ooi, T.S. Hew and K.T. Yew, The effect of convenience and speed in mpayment. Industrial Management \& Data Systems. 2014, 115(2): 311-331.

[22] A. Mohammed Abdulrahaman. Using the UTAUT Model to Determine Factors Affecting Acceptance and Use of E-government Services in the Kingdom of Saudi Arabia. School of Information and Communication Technology Science, Environment. Engineering and Technology Group Griffith University Submitted in fulfilment of the requirements of the degree of Doctor of Philosophy. 2012.

[23] V. Venkatesh, J. Y. Thong, F. K. Chan, P. J. H. Hu and S. A. Brown. Extending the two-stage information systems continuance model: Incorporating UTAUT predictors and the role of context. Information Systems Journal. 2011, 21(6): 527-555.

[24] A.N. Hidayanto, L.S. Hidadayat, P.I. Sandhyaduhita and P.W. Handayani. Examining the relationship of payment system characteristics and behavioural intention in e-payment adoption: a case of Indonesia. Int. J. Business Information Systems. 2015, 19(1): 58-56.

[25] V. Venkatesh, J. Thong, and X. Xu. Consumer acceptance and use of information technology: extending the unified theory of acceptance and use of technology. MIS Quarterly. 2012, 36(1): 157-178.

[26] S. Chandra, S. Srivastava, and Y. Theng. Evaluating the role of trust in consumer adoption of mobile payment systems: an empirical analysis. Communications of the Association for Information Systems. 2010, 27(1): 561-588.

[27] J-H, Lee and C.-H. Song. Effects of Trust and Perceived Risk on User Acceptance of a New Technology Service. Social Behavior and Personality: an international journal. 2013, 41(4): 587-597. 